\title{
Enhancing the sexual function of women living with chronic pain: A cognitive-behavioural treatment group
}

\author{
Annie Breton BScPT, Colleen M Miller PhD, Kim Fisher PhD
}

\begin{abstract}
A Breton, CM Miller, K Fisher. Enhancing the sexual function of women living with chronic pain: A cognitive-behavioural treatment group. Pain Res Manage 2008;13(3):219-224.
\end{abstract}

BACKGROUND: Chronic pain significantly impacts women's quality of life in the domain of sexual function. Treatment aimed at improving the sexual function of women living with chronic pain is minimal or absent within an interdisciplinary rehabilitation pain program.

OBJECTIVE: To evaluate a cognitive-behavioural treatment group designed to improve the sexual function of women with chronic pelvic pain, daily headache pain and neuromusculoskeletal pain within an interdisciplinary rehabilitation pain program.

METHODS: Participants were 47 women who attended the treatment group. A physical therapist and a psychologist facilitated the group. The participants completed a modified version of the Sexual Activity Questionnaire pregroup and at one month postgroup, and a Treatment Helpfulness Questionnaire at the final group session. RESULTS: All 47 women found the treatment group helpful. Sexual function improved as evidenced by significant differences (Wilcoxon signed-rank test, $\mathrm{P}<0.05$ ) from pregroup to postgroup on measures of enjoyment, lubrication, satisfaction after sexual activity and satisfaction with frequency. Improvements occurred despite no change in pain level during penetration or fatigue level from pregroup to postgroup. Treatment helpfulness results showed that women valued the knowledge and skills gained in the group. Qualitative findings suggest that a cognitive shift, and communication and partner involvement may be mechanisms of change for improved sexual function.

CONCLUSIONS: The sexual function of women with chronic pain can be significantly enhanced by a cognitive-behavioural treatment group delivered within an interdisciplinary rehabilitation pain program.

Key Words: Chronic pain; Cognitive-behavioral treatment group; Sexual function

$\mathrm{S}_{\mathrm{w}}^{\mathrm{e}}$ xual difficulties in chronic pain sufferers are frequent and wide-ranging. Prevalence rates of sexual difficulties in samples of chronic pain patients consistently range from $50 \%$ to $78 \%(1-3)$. In a study of 327 chronic pain patients $(57 \%$ of whom were female) (1), 73\% of respondents reported various difficulties with sexual activity related to chronic pain in the areas of arousal, positions, fear of exacerbating pain, lowered confidence, concerns surrounding sexual performance and decreased frequency of sexual activity. In a study of 28 women with chronic pain (4), qualitative findings highlighted concerns of partners' fear of triggering pain through

\section{Amélioration du fonctionnement sexuel des femmes aux prises avec des douleurs chroniques : Thérapie cognitivo-comportementale}

HISTORIQUE : La douleur chronique affecte significativement la qualité de vie des femmes sur le plan de la sexualité. Les traitements visant une amélioration du fonctionnement sexuel des femmes aux prises avec des douleurs chroniques sont peu nombreux, voire inexistants dans un programme interdisciplinaire de réadaptation et de prise en charge de la douleur. OBJECTIF : Évaluer un groupe soumis à une thérapie cognitivocomportementale conçue pour améliorer le fonctionnement sexuel des femmes souffrant de douleurs pelviennes chroniques, de céphalées quotidiennes ou de douleurs neuromusculosquelettiques, dans le cadre d'un programme inter-disciplinaire de réadaptation et de prise en charge de la douleur. MÉTHODES : Les participantes étaient 47 femmes qui ont accepté de suivre une thérapie de groupe. Une physiothérapeute et une psychologue étaient responsables du groupe. Les participantes ont répondu à une version modifiée du questionnaire sur l'activité sexuelle avant la première séance de groupe, un mois après les séances de groupe et elles ont ensuite répondu à un questionnaire sur l'efficacité de la thérapie lors de la dernière séance de groupe.

RÉSULTATS : Les 47 femmes ont trouvé la thérapie de groupe utile. Leur fonctionnement sexuel s'est amélioré, comme en font foi les différences significatives (test de Wilcoxon des rangs signés, $\mathrm{p}<0,05$ ) entre les mesures notées avant la thérapie et après, pour ce qui est du plaisir éprouvé, de la lubrification, du degré de satisfaction après le rapport sexuel et de la satisfaction à l'égard de la fréquence des rapports. Les améliorations sont survenues malgré l'absence de changement quant au degré de douleur à la pénétration ou au degré de fatigue entre le début et la fin de la thérapie. Les résultats au questionnaire d'évaluation du traitement ont montré que les femmes ont apprécié les connaissances et les techniques acquises en cours de route. Selon les mesures qualitatives, certains changements sur le plan cognitif et sur le plan de la communication et de la participation du partenaire seraient des mécanismes susceptibles d'améliorer le fonctionnement sexuel.

CONCLUSION : Le fonctionnement sexuel des femmes qui souffrent de douleurs chroniques peut être significativement amélioré par une thérapie de groupe cognitivo-comportementale prodiguée dans le cadre d'un programme interdisciplinaire de réadaptation et de prise en charge de la douleur.

sexual activity and for single women, hesitation about starting a new relationship. Complete cessation of sexual activity has been reported in $36 \%$ to $40 \%$ of chronic pain patients $(5,6)$.

Such research has increased awareness that chronic pain significantly impacts sexual function; in stark contrast, little information exists concerning the available treatment options for patients facing sexual difficulties associated with chronic pain. Newton-John and Brook (7) observed that it is rare to find that sexual difficulties related to chronic pain have been addressed in a multidisciplinary pain management program. 
The field of sex therapy and the treatment of sexual dysfunction are rapidly evolving. Historically, sex therapy has relied on psychoanalytic and learning theories and techniques, based on psychogenic explanations of sexual dysfunction (8). Current sex therapy approaches integrate cognitive, systemic and behavioural therapy techniques (9). Today, sexual medicine is embracing a multifactorial understanding of sexual dysfunction within an interdisciplinary treatment model.

One randomized, controlled treatment outcome study (10) exists concerning the efficacy of cognitive-behavioural group treatment for the pain disorder of dyspareunia, previously viewed as a sexual dysfunction disorder. Bergeron et al (10) randomly assigned 78 women with dyspareunia, resulting from vulvar vestibulitis, to one of three treatment conditions group cognitive-behavioural treatment, surface electromyographic feedback and vestibulectomy. Results showed that all three treatment groups significantly improved on measures of psychological adjustment and sexual function.

Both health care providers and patients may collude to avoid the topic of sexual difficulties, not only because of personal discomfort but also because of lack of treatment options $(11,12)$. Ambler et al $(1)$ surveyed 30 men and 38 women with chronic pain about their preferences for such treatment and found interest in information-only and information plus discussion venues. Of those preferring a discussion venue, preference for individual or group formats was split about equally; the survey found no difference based on the sex of respondent.

Cognitive-behavioural group treatment specifically designed to address women's sexual difficulties related to chronic pain in an interdisciplinary rehabilitation pain program is scant or nonexistent. The aim of the present program evaluation project within an interdisciplinary rehabilitation pain program was to design, deliver and evaluate such a group treatment.

\section{METHODS}

\section{Participants}

The Calgary Health Region Chronic Pain Centre (CHR CPC) is a publicly funded service that integrates medical management, rehabilitation and self-management approaches to the treatment of chronic pain in individual and group formats in an interdisciplinary setting. Participants were women who, during the course of their treatment at the CHR CPC, referred themselves to the cognitive-behavioural treatment group (known as the Intimacy Group). The treatment group was open to women with neuromusculoskeletal pain, chronic pelvic pain and daily headache pain. Women were informed of the Intimacy Group through the recommendation of an interdisciplinary team member or through information about the group posted in the CHR CPC.

\section{Measures}

Two questionnaires were administered to the group participants; women were also asked to record their age.

The Sexual Activity Questionnaire: The Sexual Activity Questionnaire (SAQ) is a 13-item measure of women's sexual function, designed to be nonintrusive and acceptable to women with gynecological disorders $(13,14)$. The SAQ has high test-retest reliability, discriminative validity and good face validity (13). With permission from the author, the introductory instructions were modified for a chronic pain population (personal communication, October 19, 2000). One item concerns whether a woman was currently sexually active. If sexually active, a further series of 10 items concern dimensions of her sexual experience during the past month. Responses to all 10 items were categorical; for example, for the item "Did you enjoy sexual activity this month?" the responses were $3=$ 'very much', 2 = 'somewhat', 1 = 'a little' and $0=$ 'not at all'.

Treatment Helpfulness Questionnaire: The Treatment Helpfulness Questionnaire (THQ) is a 10-item measure of women's perceived helpfulness of the treatment group which was developed by the authors for the purpose of this project. Women rated the degree to which the treatment group helped in the realms of knowledge, skills, and pain management on a scale from 1 (strongly agree) to 5 (strongly disagree). Questions were posed in the format "As a result of the Intimacy Group, I am better able to communicate my sexual needs to my partner". In addition, participants were invited to provide written comments on each item.

\section{Treatment group}

The treatment group consisted of four $2 \mathrm{~h}$ sessions over the course of four consecutive weeks. The treatment approach integrated cognitive-behavioural treatment for chronic pain (15), brief sex counselling (16) and a self-management approach (17). The group was purposely cofacilitated by a physical therapist and a psychologist to provide an interdisciplinary approach and guard against the historical trend to dichotomize pain or sexual function into either the psychological or the physical domains (18-20).

The group content included topics such as the impact of chronic pain on sexual function, societal myths related to sexuality, the pleasure model (21), communication, sensate focus (22), pelvic floor muscles, relaxation techniques and positions. Participants were given take-home assignments and encouraged to involve their partner in the take-home assignments and to share what they had learned in the group.

\section{Procedure}

Women were invited to participate anonymously in the program evaluation project by completing the questionnaires. The SAQ was administered pregroup at session 1 before the start of treatment and at a postgroup session one month after the completion of the group. The THQ was administered at the end of the final (fourth) session of the treatment group.

\section{Group participants}

\section{RESULTS}

Over the course of the project, 62 women registered in the Intimacy Group. Four women dropped out of the group; reasons given for withdrawal from the group included ill health and scheduling conflicts. Of the remaining 58 women who completed the group, 11 women did not complete all questionnaires because they were absent the session during which the questionnaire was administered. Thus, in total, 47 women completed the THQ and 44 women completed both the pregroup SAQ and the postgroup SAQ. Of the 47 women, 35 (75\%) had chronic pelvic pain, nine (19\%) had neuromusculoskeletal pain and three $(6 \%)$ had daily headache pain. The women ranged in age from 20 to 61 years, with a mean age of 38.73 years. In total, 10 groups were delivered with three to six participants per group. 
TABLE 1

Reasons identified for not being sexually active

\begin{tabular}{lcc}
\hline Reasons & Pregroup $(\mathbf{n}=\mathbf{1 8})$ & Postgroup $(\mathbf{n = 1 3})$ \\
\hline No partner & 3 & 3 \\
Too tired & 8 & 4 \\
Partner too tired & 2 & 1 \\
Not interested in sex & 8 & 6 \\
Partner not interested in sex & 0 & 1 \\
Physical problem & 15 & 9 \\
Partner physical problem & 1 & 0 \\
Other reasons & 2 & 1
\end{tabular}

The table contains the number of women who identified the reason provided. Women could identify more than one reason

\section{Outcome of group treatment}

Forty-four women completed the SAQ pregroup and postgroup. In terms of presence or absence of sexual activity, $41 \%$ (18 of 44) of the women were not sexually active before the group. Table 1 shows the reasons identified for not being sexually active. The most common constellation of reasons was too tired, not interested in sex and physical problem. Of the 18 women who were not sexually active in the month before the group, two did not have partners pre- or postgroup. The third woman who did not have a partner at pregroup had a partner at postgroup. Thus, of the sexually inactive women who had a partner pre- and postgroup, $44 \%$ (seven of 16) of these women became sexually active after the group. Two women who were sexually active before the group became sexually inactive after the group; one woman provided the reason of no partner (ie, separation), and the other woman provided the triad of reasons of too tired, not interested in sex and physical problem.

In the subsample of women who were sexually active preand postgroup $(n=24)$, the Wilcoxon signed-rank test, a nonparametric test for categorical data, showed significant differences on items of enjoyment, vaginal dryness, satisfaction after sexual activity and satisfaction with frequency, indicating improvement on these dimensions of their sexual experience (Table 2).

No significant differences were found in pre- and postscores on the items of pain and fatigue, or on items of importance of sex, desire, frequency and usual frequency.

An analysis of outcome based on pain site (ie, chronic pelvic pain versus neuromusculoskeletal versus daily headache pain) could not be conducted due to insufficient grouped data.

\section{Helpfulness of group treatment}

Forty-seven women completed the THQ. The majority of women found all of the knowledge and skills imparted during group treatment helpful (Table 3). Over $90 \%$ of the women agreed or strongly agreed that the following concepts or strategies were helpful - myths related to sexuality, physiology of the sexual response, understanding how pain affects sexuality, communication, role of relaxation and a broader view of sexuality. Women seemed to agree or strongly agree to a lesser extent about the helpfulness of the pelvic floor muscles and sensate focus exercises

In terms of overall helpfulness of the group, $100 \%$ of the group participants strongly agreed $(75 \%)$ or agreed $(25 \%)$ that

\section{TABLE 2}

Wilcoxon signed-rank test for the Sexual Activity Questionnaire (SAQ)

\begin{tabular}{ll}
\hline SAQ item & $\mathbf{P}$ \\
\hline Was having sex an important part of your life this month? & 0.222 \\
Did you enjoy sexual activity this month? & $0.045^{\star}$ \\
In general, were you too tired to have sex? & 1.00 \\
Did you desire to have sex with your partner(s) this month? & 0.739 \\
During sexual relations, how frequently did you notice dryness of & $0.003^{\star *}$ \\
$\quad$ your vagina? & 0.166 \\
Did you feel pain or discomfort during penetration this month? & $0.008^{\star *}$ \\
In general, did you feel satisfied after sexual activity this month? & 0.414 \\
How often did you engage in sexual activity this month? & 0.272 \\
How did this frequency of sexual activity compare with what is & \\
$\quad$ usual for you? & \\
Were you satisfied with the frequency of sexual activity this month? & $0.008^{\star *}$
\end{tabular}

Were you satisfied with the frequency of sexual activity this month? $0.008^{\star *}$

${ }^{*} P<0.05 ;{ }^{* *} P<0.01$

\section{TABLE 3}

\section{Treatment Helpfulness Questionnaire (THQ) items}

\begin{tabular}{lc}
\hline THQ item & $\begin{array}{c}\text { \% Agree or } \\
\text { strongly agree } \\
\text { ( } \mathbf{n = 4 7 )}\end{array}$ \\
\hline As a result of the intimacy group: & 93 \\
I have a better understanding of myths related to sexuality & 92 \\
I understand the physiology of the sexual response & 91 \\
I have a better understanding of how pain affects my sexuality & 91 \\
I am better able to communicate my sexual needs to my partner & 91 \\
My partner and I found the sensate focus exercise helpful & 64 \\
I have been using the pelvic floor muscle exercises & 62 \\
I am aware of the role of relaxation in the sexual response & 98 \\
I am better able to manage pain that arises during or after & 74 \\
sexual activity & 97 \\
I have a broader view of sexuality & 100 \\
I found the intimacy group to be helpful and of value to me & \\
\hline
\end{tabular}

the group was helpful and of value to them. Seventy-four per cent of the women felt better able to manage pain around sexual activity.

Experience of group treatment

Women's written comments in response to the THQ were considered data. Data analysis involved breaking down the data and then reorganizing the data into thematic and conceptual categories $(23,24)$. Analysis of women's written comments resulted in the thematic and conceptual categories shown in Table 4.

The category of 'pain impact' revealed women's increased awareness of the impact of pain on sexual function. Women's gain in understanding seemed to arise out of being able to identify specific aspects of interference, such as quality, quantity, frequency and desire. Others simply experienced an increased awareness of the effects of pain on sexual function. One woman suggested that pain did not play a primary role in impacting sexual function. 
TABLE 4

Thematic and conceptual results of women's written comments on the Treatment Helpfulness Questionnaire

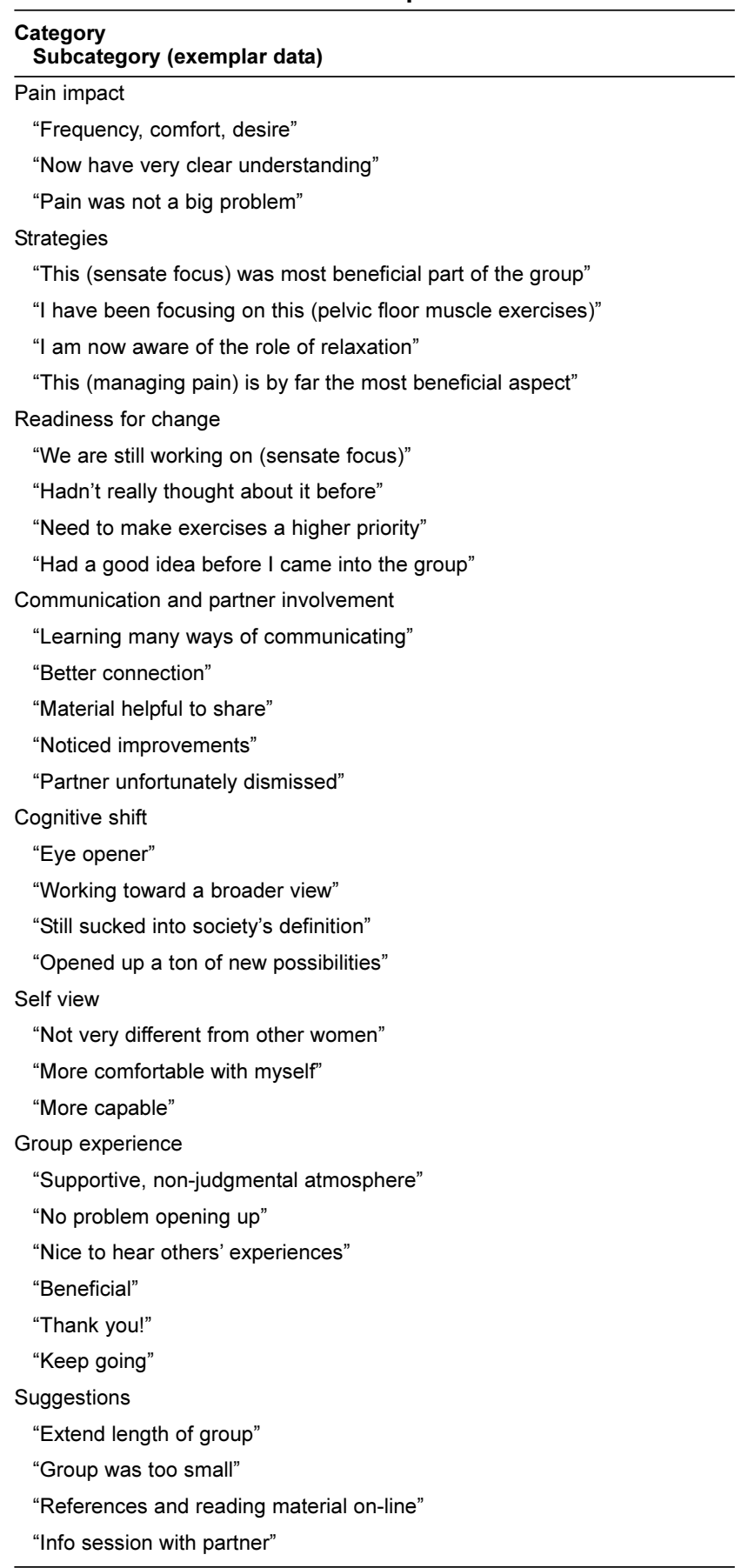

Women noted the value of specific 'strategies' for managing pain related to sexual activity, such as sensate focus, pelvic floor muscle exercises, relaxation and managing pain around sexual activity (ie, rest following sexual activity).

The closely related category of 'readiness for change' showed the variation in women's adoption of strategies including working on a particular strategy, a new awareness of the relevance of a strategy, the awareness of the need to make implementation of a strategy a higher priority and previous knowledge of strategies reaffirmed.

Beyond specific strategies, the category of 'communication and partner involvement' highlighted a variety of aspects such as learning to communicate more openly, experiencing a better connection with her partner, the helpfulness of sharing information with a partner and noticing improvements in the couple's sexual function. One woman's comments revealed that her partner dismissed a strategy as unnecessary (ie, sensate focus). In response to the topic of communication, another woman disclosed she invited her partner to attend counselling to address intimacy problems in their relationship.

The category of 'cognitive shift' showed that women experienced the group as "eye-opening". Some women were explicit that they were working towards a broader view of sexuality (ie, from goal-orientated to pleasure-oriented). Others acknowledged being greatly influenced by cultural expectations concerning sexual function. Women also identified the opening up of possibilities or avenues for dealing with the impact of pain on sexual function.

The closely related category of 'self view' suggested that women changed their view of self as it pertains to sexual function as a result of participating in the group. In this category, women recognized that they were not very different from each other in the experience of pain impact on sexual function. In addition, women described increased comfort with themselves and an increased sense of competence in addressing the problem of pain impact on sexual function.

Finally, the category of 'group experience' revealed the extent to which women valued the group experience. Women seemed surprised at their comfort and ability to disclose in the group, they identified the benefit received and voiced their appreciation of the group.

In addition, women had suggestions for future development of the group, including extending the length of the group, more references and direct partner involvement.

\section{DISCUSSION}

Sexual functioning of women with chronic pain can be significantly enhanced through a cognitive-behavioural treatment group designed to target pain impact on sexual function. The delivery of such a treatment group within an interdisciplinary chronic pain rehabilitation program is a considerable advancement, perhaps the first of its kind in a publicly funded service. The evidence from this program evaluation project suggests that the group is needed, perceived as helpful and results in improved sexual function.

Almost one-half of the women who identified themselves as being sexually inactive before the group became sexually active following the group treatment. Such a promising rate of return to sexual activity is notable, given the high proportion of women with chronic pain who report complete cessation of sexual activity. In a post hoc analysis of a separate sample of 553 women in the same setting on the Pain Disability Index, a measure of disability due to pain, one in five women rated the interference of pain on sexual behaviour in the complete or total disability range (25).

For those women who were sexually active before and after the group, greater enjoyment and satisfaction were markers of improved sexual function, and this is despite no change in pain or fatigue levels. Such markers of sexual function for women 
are in line with recent advances in understanding women's sexual function in broader terms shifting from a goal-oriented model (ie, penetration and orgasm) towards a pleasureoriented model (ie, enjoyment and satisfaction) $(21,26)$. The absence of improvement in pain level or fatigue level is consistent with typical rehabilitation goals of self-management of pain, to improve function while managing pain and fatigue.

The finding of decreased vaginal dryness or increased lubrication during sexual activity may indicate decreased fear of pain during sexual activity. Fear of movement, pain catastrophizing and avoidance of activity (ie, exercise, work) are targets for rehabilitation treatments for chronic pain $(27,28)$. Approaching sexual activity and decreasing fear of pain related to sexual activity are parallel goals in the domain of sexual function.

Satisfaction with frequency of sexual activity despite the lack of an actual increase in frequency of sexual activity may suggest an adaptive restructuring of expectations concerning frequency. Such a hypothesis falls in line with notions of adaptation to chronic pain, including acceptance of limitations that may extend into managing pain in the realm of sexual function. An alternative explanation for the finding of satisfaction with frequency may be a redefining or broadening of what constitutes sexual activity from solely penetrative activities to include nonpenetrative activities.

The qualitative data highlight that women valued the treatment group and experienced the group as beneficial. Women valued the knowledge and skills imparted, but equally the supportive and validating presence of other women with the same problem. As such, group dynamics that involve therapeutic factors such as universality, installation of hope, selfunderstanding, and interpersonal input and output may well have contributed to women's perceived benefit of the group (29).

Furthermore, women's comments speak to potential mechanisms of change as it pertains to mitigating the effects of pain on sexual function. Possible mechanisms of change include the women's cognitive shift, and communication and partner involvement.

Women seemed to experience a cognitive shift in view of self, from isolation and stigmatization to social connection and empowerment. In turn, women described feeling more comfortable and more competent to address the impact of pain on sexual function. Women's view of the problem seemed to shift from limited options to a broadened view of what constitutes a sexually satisfying relationship.

Communication and partner involvement seemed to be another possible mechanism of change. Self-management of pain often includes assertiveness training and communication of needs as it pertains to managing pain in daily activities (17).

Interestingly, women seemed aware of their own readiness for making changes and implementing strategies to manage the impact of pain on sexual function. Women described stages of change including the precontemplation, contemplation, action and maintenance stages $(30,31)$.

When developing this group, we consulted colleagues with expertise in chronic pain, sex therapy and groups, and the women themselves, and learned that women preferred a women-only forum. Women preferred the women-only forum if they were in an unstable relationship, if their partner was not open or supportive, or if they were currently single. While the issue of pain impact on sexual function is well-known for women with chronic pelvic pain, we decided to open the group to women with daily headache pain and neuromusculoskeletal pain, as well. Bringing together women with different pain sites seemed to enhance women's understanding of pain, its effects and its management. Interestingly, Laursen et al (32) found no difference in frequency of intercourse between the patient groups of low back pain, fibromyalgia and whiplash, endometriosis, and arthritis.

As group facilitators, we observed that the group has been well received. The women routinely express gratefulness for the group experience. Moreover, they seemed to benefit both from the skill-building component of the group as well as the interactive and supportive component of the group. Interestingly, women themselves observed that such a group may be indicated for women without pain, which may speak to the cultural expectations concerning sexual function that may not only limit women with a chronic condition, but women, generally.

We noted that women with chronic pelvic pain constituted the majority of the group participants. However, we anticipate that with more awareness and comfort among interdisciplinary team members concerning the problem of sexual difficulties in chronic pain, the proportion of women with other pain sites participating in this treatment would increase. We also observed variations in pain impact on sexual function among women with different pain sites. For women with chronic pelvic pain, painful intercourse and fear of pain were frequent complaints. For women with daily headache pain, fatigue and low desire were of concern. While intriguing, we are unable to comment on how the group may have had differential benefits for women with various pain sites.

Limitations of this program evaluation project include a self-selected sample, the absence of a comparison control group, and a short follow-up period. Also, while techniques for minimizing type 1 errors are well established for parametric tests, we are not aware of any method that reduces the probability of the experimentwise error when using the Wilcoxon signed-rank test. Although the risk of experimentwise error is false positives, three of the four positive results were at the more stringent level of $\mathrm{P}<0.01$. For the purposes of piloting a new treatment group, the results are notable and worthy of future research.

Future research would serve to replicate the findings with a control group, compare treatment outcome among pain sites, extend the follow-up period to ascertain durability of improvement, validate the mechanisms of change and include partners' experiences.

\section{CONCLUSIONS}

A cognitive-behavioural treatment group appears effective in the management of pain impact on sexual function for women with chronic pain in an interdisciplinary rehabilitation pain program

ACKNOWLEDGEMENTS: The authors gratefully acknowledge group participants for their contributions; Marelize Swartz and Elke Reissing, colleagues in the community, for their expertise during the development of the group; and Geoff Schultz, colleague at the CHR CPC, for providing the analysis of Pain Disability Index data. 


\section{REFERENCES}

1. Ambler N, Williams AC, Hill P, Gunary R, Cratchley G. Sexual difficulties of chronic pain patients. Clin J Pain 2001;17:138-45.

2. Maruta T, Osborne D, Swanson DW. Chronic pain patients and spouses: Marital and sexual adjustment. Mayo Clinic Proc 1981;56:307-10.

3. Maruta T, Osborne D. Sexual activity in chronic pain patients. Psychosomatics 1978;19:531-7.

4. Schlesinger L. Chronic pain, intimacy, and sexuality: A qualitative study of women who live with pain. J Sex Res 1996:33:249-56.

5. Coates R, Ferroni PA. Sexual dysfunction and marital disharmony as a consequence of chronic lumbar spinal pain. Sex Marital Ther $1991 ; 6: 65-9$.

6. Flor H, Turk DC, Scholz O. Impact of chronic pain on the spouse: Marital, emotional and physical consequences. J Psychosom Res 1987;31:63-71.

7. Newton-John T, Brook S. Treating sexual dysfunction in chronic pain patients. In: Gifford L, ed. Topical Issues in Pain 2: Biopsychosocial Assessment and Management: Relationships and Pain. Cornwall: CNS Press, 2000:177-86.

8. Kaplan HK. The New Sex Therapy: Active Treatment of Sexual Dysfunctions. New York: Brunner/Mazel Pubs, 1974:1-4.

9. Pridal CG, LoPiccolo J. Multielement treatment of desire disorders: Integration of cognitive, behavioral and systemic therapy. In: Leiblum SR, Rosen RC, eds. Principles and Practice of Sex Therapy. New York: Guildford Press, 2000:57-81.

10. Bergeron S, Binik YM, Khalifé S, et al. A randomized comparison of group cognitive-behavioral therapy, surface electromyographic biofeedback, and vestibulectomy in the treatment of dyspareunia resulting from vulvar vestibulitis. Pain 2001;91:297-306.

11. Paice J. Sexuality and chronic pain. Am J Nurs 2003;103:87-9.

12. Fleming M, Paice J. Sexuality and chronic pain. J Sex Educ Ther 2001;26:204-14.

13. Thirlaway K, Fallowfield L, Cuzik J. The Sexual Activity Questionnaire: A measure of women's sexual functioning. Qual Life Res 1996;15:81-90.

14. Stead ML, Crocombe WD, Fallowfield LJ, et al. Sexual activity questionnaires in clinical trials: acceptability to patients with gynaecological disorders. Br J Obstet Gynaecol 1999;106:50-4.

15. Turk DC. A cognitive-behavioral perspective on treatment of chronic pain patients. In: Turk DC, Gatchel RJ, eds. Psychological Approaches to Pain Management: A Practitioner's Handbook. New York: Guilford Press, 2002:138-58.
16. Schover L. Sexual problems in chronic illness. In: Leiblum SR, Rosen RC, eds. Principles and Practice of Sex Therapy. New York: Guildford Press, 2000;398-422.

17. Hanson RW. Gerber KE. Coping with Chronic Pain: A Guide to Patient Self-Management. New York: Guilford Press, 1990:45-79.

18. Grace VM. Mind/body dualism in medicine: the case of chronic pelvic pain without organic pathology: A critical review of the literature. Int J Health Serv 1998;28:127-51.

19. Meana M, Binik YM, Khalife S, Cohen D. Dyspareunia: Sexual dysfunction or pain syndrome? J Nerv Ment Dis 1997;185:561-9.

20. Binik YM, Pukall CF, Reissing ED, Khalife S. The sexual pain disorders: A desexualized approach. J Sex Marital Ther 2001;27:113-6.

21. Whipple B. Beyond the G spot: New research on human female sexual anatomy and physiology. Scand J Sexology 2000;3:35-42.

22. Althof SE. Erectile dysfunction: Psychotherapy with men and couples. In: Leiblum SR, Rosen RC, eds. Principles and Practice of Sex Therapy. New York: Guildford Press, 2000:242-75.

23. Taylor SJ, Bogdan R. Introduction to Qualitative Research Methods: The Search for Meanings. New York: Wiley-Interscience Publication, 1984:123-45.

24. Tesch R. Qualitative research: Analysis types and software tools. New York: The Falmer Press, 1990:135-46.

25. Tait RC, Chibnall JT, Krause S. The Pain Disability Index: Psychometric properties. Pain 1990;40:171-82.

26. Basson R. Recent advances in women's sexual function and dysfunction. Menopause 2004;11(Suppl):714-25.

27. Sullivan MJ, Bishop SR, Pivik J. The Pain Catastrophizing Scale: Development and validation. Psych Assess 1995;7:524-32.

28. Crombez G, Vlaeyen JW, Heuts PH, Lysens R. Pain-related fear is more disabling than pain itself: evidence on the role of pain-related fear in chronic back pain disability. Pain 1999;80:329-39.

29. Yalom ID. The Theory and Practice of Group Psychotherapy. New York: Basic Books, 1985:70-111.

30. Prochaska JO, DiClemente CC. Stages of change in the modification of problem behaviors. In: Hersen M, Eisler RM, Miller PM, eds. Progress in Behavior Modification. Sycamore, Illinois: Sycamore Press, 1992:183-218.

31. Kerns RD, Habib S. A critical review of the pain readiness to change model. J Pain 2004;5:357-67.

32. Laursen BS, Overvad K, Olesen AS, Delmar C, Arendt-Nielsen L. Ongoing pain, sexual desire, and frequency of sexual intercourse in females with different chronic pain syndromes. Sex Disabil $2006 ; 24: 27-37$. 


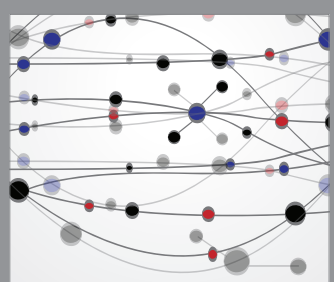

The Scientific World Journal
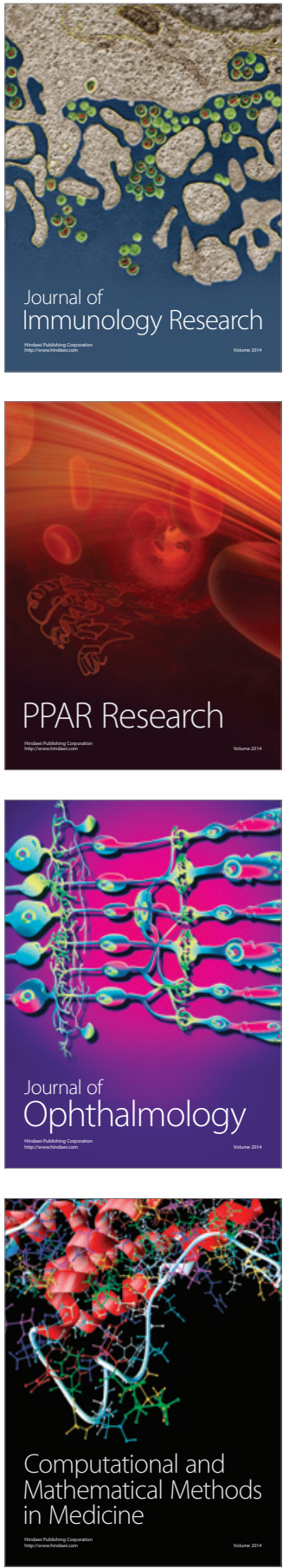

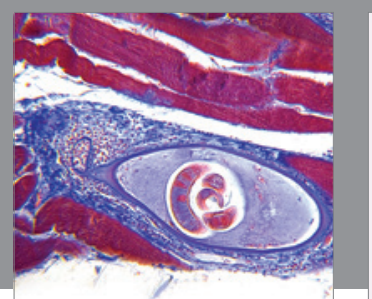

Gastroenterology Research and Practice

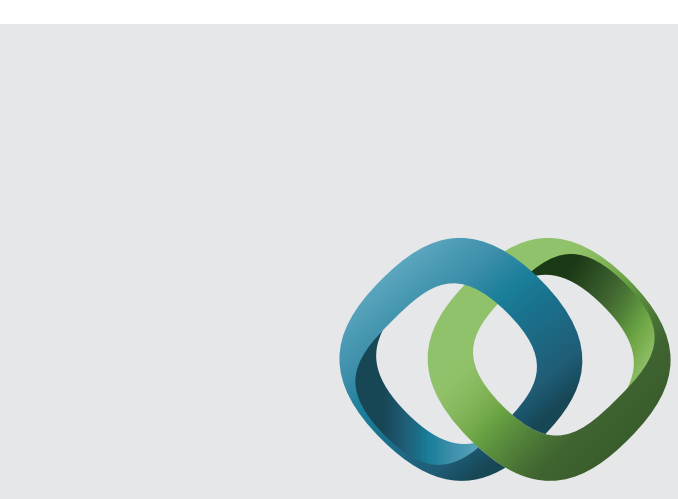

\section{Hindawi}

Submit your manuscripts at

http://www.hindawi.com
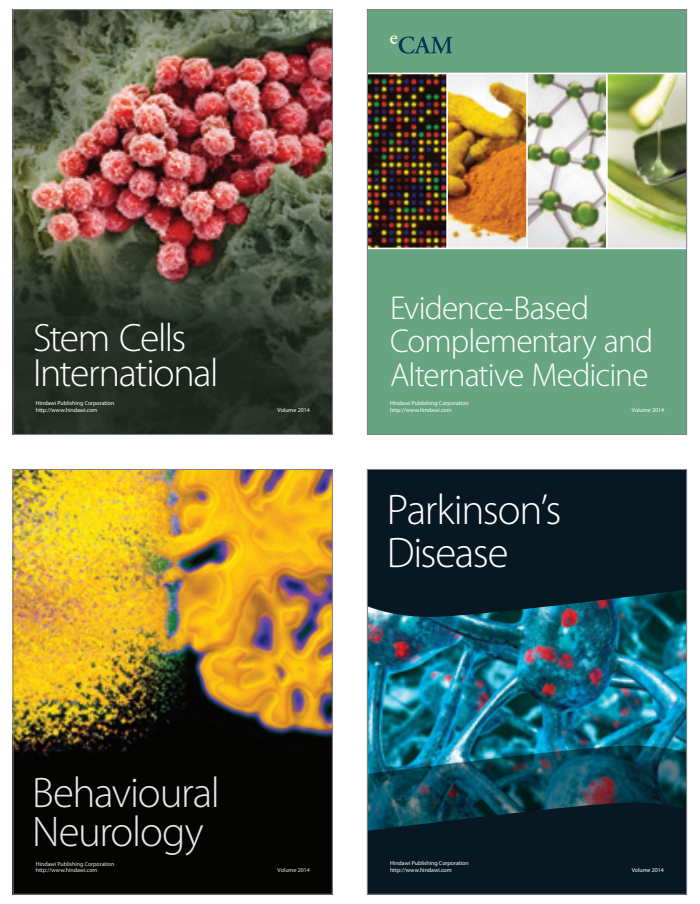
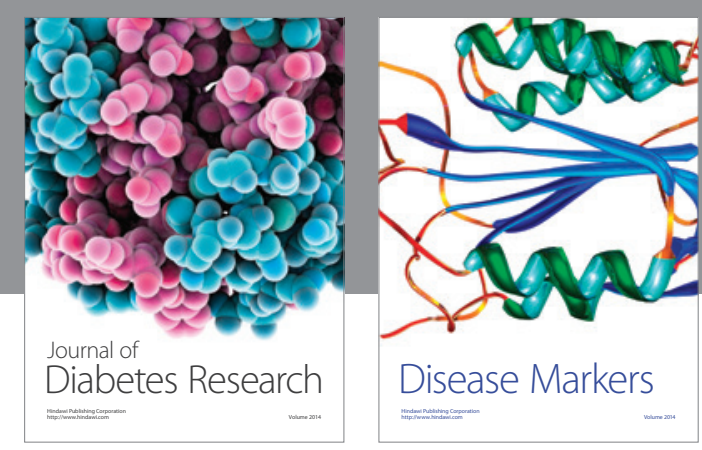

Disease Markers
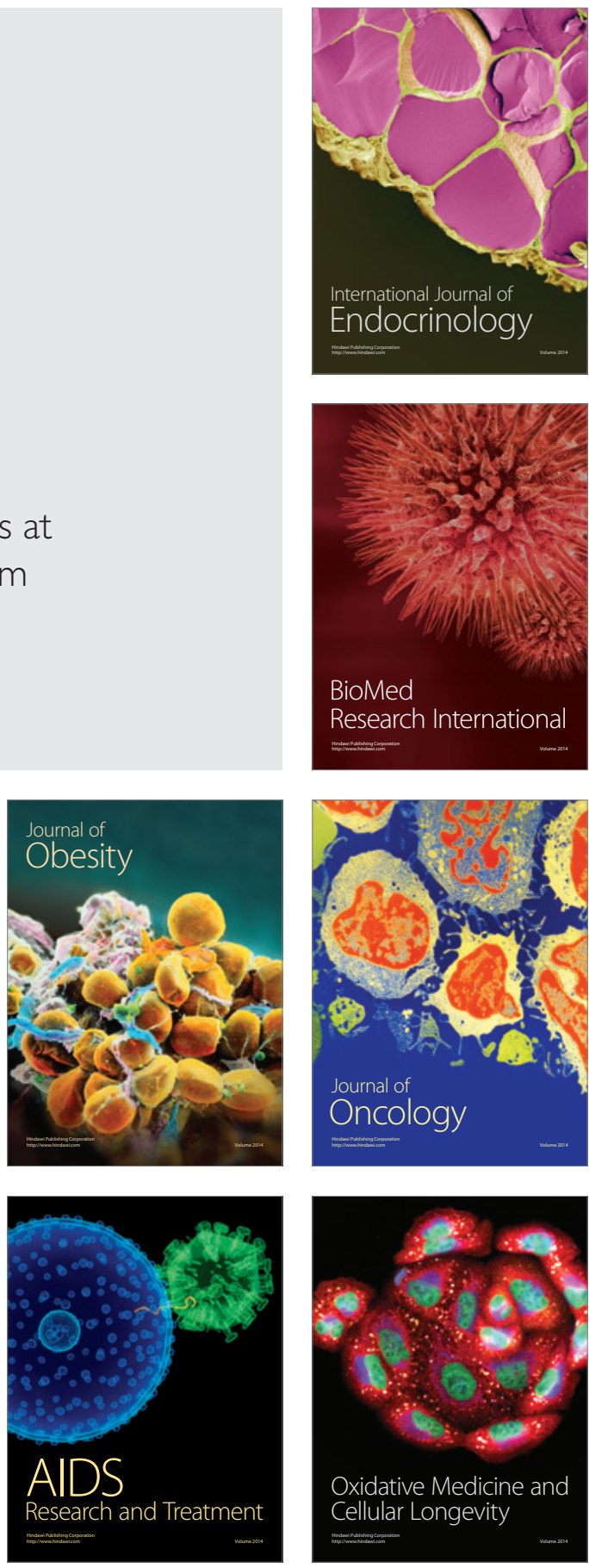